\title{
O ENSINO DE BIOLOGIA CELULAR: UMAANÁLISE EM EVENTOS DA ÁREA
}

The Teaching of Cellular Biology: an Analysis in Area Events

Laura Oestreich ${ }^{1}$

Andréa Inês Goldschmidt ${ }^{2}$

\begin{abstract}
Resumo: Nosso objetivo foi investigar os rumos das pesquisas no ensino de biologia celular em dois eventos de relevância da área: os congressos promovidos pela Sociedade Brasileira de Biologia Celular (SBBC) e o Encontro Nacional de Pesquisa em Educação em Ciências (ENPEC). Esta pesquisa de caráter exploratório consistiu na realização de um 'estado do conhecimento' e analisou 58 trabalhos, os quais foram agrupados em 12 categorias de análise. Os resultados sinalizaram um aumento no número de trabalhos voltados para a área ao longo dos anos de 2015 a 2019, sendo que em 2015 foram apresentados nove trabalhos e em 2019, 13 artigos. Ainda assim, no ano de 2018 foram apresentados 18 trabalhos, o que evidencia um decréscimo no número de trabalhos no ano de 2019. As categorias Modelos Didáticos (20,7\%), Ferramentas Digitais de Aprendizagem (12,1\%) e Concepções Sobre Citologia $(12,1 \%)$ foram os focos mais pesquisados nos trabalhos analisados. Na contramão, as categorias Análise de Livro Didático (3,4\%) e Textos de Divulgação Científica $(3,4 \%)$ obtiveram percentuais pouco expressivos. Ao final, reiteramos a importância da realização de novas pesquisas na área e sinalizamos um estado de alerta, tendo em vista a diminuição no número de trabalhos apresentados no ano de 2019, fato que pode estar ligado aos recorrentes cortes de bolsas de pesquisa e financiamento de projetos, o que inviabiliza parte do trabalho dos pesquisadores e avanços na área.
\end{abstract}

Palavras-chave: Ensino de biologia. Estado do conhecimento. Citologia.

Abstract: Our objective was to investigate the direction of research in the teaching of cell biology in two events of relevance in the area: the congresses promoted by the Brazilian Society of Cell Biology (SBBC) and the National Research Meeting in Science Education (ENPEC). This exploratory research consisted of carrying out a 'state of knowledge' and analyzed 58 works, which were grouped into 12 categories of analysis. The results signaled an increase in the number of works focused on the area throughout 2015 and 2019, with 9 papers being presented in 2015 and 13 articles in 2019, although 18 papers were presented in 2018, which shows a decrease in the number of papers in 2019. The Didactic Models $(20.7 \%)$, Digital Learning Tools (12.1\%); and Conceptions about Cytology (12.1\%) categories were the most researched focuses in the analyzed studies. In the opposite direction, the categories Didactic Book Analysis (3.4\%) and Scientific Dissemination Texts (3.4\%) had low percentages. In the end, we reiterate the importance of conducting new research in the area

\footnotetext{
1 Doutoranda em Educação em Ciências: Química da Vida e Saúde (UFSM), Orcid: https://orcid.org/0000-0001-5684-1149.E-mail: lauraoestreich@hotmail.com

${ }^{2}$ Doutora em Educação em Ciências: Química da Vida e Saúde (UFSM). Professora Adjunta no Departamento de Zootecnia e Ciências Biológicas da Universidade Federal de Santa Maria - Campus Palmeira das Missões (RS) e Professora no Programa de Pós-Graduação em Educação em Ciências: Química da Vida e Saúde (USFM). Orcid: https://orcid.org/0000-0001-8263-7539. E-mail: andreainesgold@gmail.com
} 
and signal a warning because of the decrease in the number of papers presented in 2019, a fact that may be linked to the recurrent cuts in research grants and funding of projects which makes part of the researchers' work and advances in the area unfeasible.

Keywords: Biology teaching. State of knowledge. Cytology.

\section{Introdução}

A biologia celular é uma subárea da biologia de extrema importância, pois se volta para o estudo das células e seu funcionamento. Logo, introduz uma gama de conceitos essenciais para o entendimento de diversos processos que ocorrem nos seres vivos. Alberts et al. (2017, p. 20) explicam que "vivemos em um mundo que nos apresenta vários assuntos complexos relacionados à biologia celular: biodiversidade, mudança climática, segurança alimentar, degradação ambiental, esgotamento de fontes de recursos e doenças". Isto é, a biologia celular para além do entendimento da diferenciação das células animais e vegetais é bem mais abrangente, envolvendo outras áreas biológicas, como a zoologia, a botânica, a microbiologia, a ecologia e tantas outras.

Ainda que envolva toda essa dimensão, a forma como a biologia celular é trabalhada se volta para a fragmentação dos conceitos e pouca ou nenhuma contextualização entre as diversas áreas. Sobre isso, Vigário e Cicillini (2019, p. 59) afirmam que:

É evidente que a Biologia Celular permanece nos currículos da educação básica e do
ensino superior mais pela força acadêmica do que pela natureza interdisciplinar e
pela fluidez em conduzir a construção do conhecimento sobre a vida e os seres
vivos. Todavia, mesmo ao constatarmos tal fato no currículo disciplinar da educação
básica, entendemos a importância da Biologia Celular como forma de transcender a
fragmentação curricular das áreas e dos conteúdos e adentrar uma Biologia do
perceptível, vivenciado, bem como da construção de significados sobre a
diversidade da vida. A Biologia Celular é a ponte para a compreensão dos
fenômenos orgânicos dos seres vivos e suas relações com o ambiente.

Ademais, Vigário e Cicillini (2019) ainda explicam que o próprio currículo e os materiais didáticos da biologia possuem um perfil desintegrado. Tal colocação se torna ainda mais relevante ao ressaltarmos que a biologia celular costuma ser o primeiro contato que o aluno tem com a disciplina de biologia. Sendo assim, é através desse conteúdo que é possível ganhar a paixão do aluno por esta disciplina/área.

Entretanto, ensinar biologia celular não é uma tarefa fácil, uma vez que se trata de algo invisível a olho nu, e mesmo quando se tem possibilidade de visualizar uma célula através da microscopia o conteúdo ainda permanece abstrato, considerando toda a complexidade dos processos e organelas celulares que raramente podem ser observadas. Nesse sentido, Vigário e Cicillini $(2019$, p. 62) afirmam que "ensinar e aprender não são tarefas fáceis, principalmente quando é preciso partir da abstração sobre um assunto para chegar à concretização de um conceito ou processo".

Todavia, Glaser, Pierre e Lara-Fioreze (2017) pontuam que por vezes os conteúdos relacionados à biologia celular são trabalhados de forma meramente teórica, pois a realidade das escolas brasileiras se volta para a inexistência de microscópios e laboratórios científicos e, quando existem, em certas ocasiões são precários, com pouca estrutura física e com ausência 
de materiais de consumo. Nascimento (2016) sinaliza que o custo elevado de equipamentos que permitem analisar estruturas microscópicas atua como barreira para as instituições de ensino básico adquirirem esses materiais. A autora ainda afirma que, segundo o Censo da Educação Básica de 2009, divulgados pelo Instituto Nacional de Estudos e Pesquisas Educacionais Anísio Teixeira (INEP), apenas 21,5\% das escolas de Ensino Fundamental possuíam laboratório de Ciências. Nos censos posteriores este item não foi avaliado e, assim, pouco se sabe sobre como estão ou não equipadas as escolas de educação básica atualmente. Ademais, a falta de investimentos tem sido também, um dos fatores que contribuem para índices cada vez mais altos de alunos desmotivados e desinteressados na área científica.

Importa destacar que já existem alternativas na tentativa de superar essas dificuldades. Professores, por vezes, confeccionam materiais diversificados para que os alunos possam, de alguma forma, ter contato com um microscópio ou um modelo celular. Dessa maneira, diversos autores têm apresentado possibilidades para a criação de materiais alternativos. Silva, Baltar e Bezerra (2019), em seu estudo, criaram um microscópio artesanal, testaram corantes alimentícios para a visualização de estruturas celulares e concluíram que o material construído é eficiente para o ensino de biologia celular. Sepel, Rocha e Loreto (2011) e Wallau et al. (2008) demonstraram como construir um microscópio bastante simples e semelhante aos primeiros microscópios utilizados por Leeuwenhoek e Hooke, de modo que isso possibilita que cada aluno possa construir o seu equipamento, além de estimular a discussão de aspectos ligados à história da ciência.

No campo da criação de modelos didáticos celulares não vem sendo diferente. Diversos autores têm indicado caminhos para diminuir a abstração do conteúdo e permitir uma melhor compreensão dos conceitos de biologia celular. Santana e Santos (2019), em artigo de revisão bibliográfica, discutem acerca de oito trabalhos voltados para a criação de modelos celulares. Assim, os trabalhos se voltam para a criação de modelos de células comestíveis, células confeccionadas por meio de materiais de baixo custo, como papel cartão, lápis de cor, cola e tesoura, e modelos celulares tridimensionais. Os autores apontam que esses recursos facilitaram o entendimento do conteúdo de biologia celular, tornando-o mais 'palpável', o que permite aos alunos interagirem entre si e também com o professor.

Outra problemática encontrada é levantada por Carlan, Sepel e Loreto (2013), ao confirmarem, após investigação com os docentes, que ainda ocorre a utilização do livro didático como único recurso para o planejamento das aulas. Assim, os conceitos e termos acabam sendo apenas memorizados, o que inviabiliza uma aprendizagem significativa. Para a superação dessa dificuldade, os autores sugerem a formação continuada como opção viável, o incentivo ao emprego de diversos recursos didáticos para ensinar biologia celular, bem como a contextualização do conteúdo com o cotidiano dos estudantes, por meio da exploração de assuntos como cicatrização e o crescimento do indivíduo. Entretanto, Glaser, Pierre e Lara-Fioreze (2017) explicam que a falta de tempo para o planejamento de aulas, as longas jornadas de trabalho em diferentes escolas, bem como a carga excessiva de conteúdo, raramente tornam possível que o professor consiga confeccionar estes materiais.

Neste contexto, diversos estudos têm se voltado para o ensino de biologia celular, buscando sanar dificuldades da área. Por isso, com o presente trabalho, nosso objetivo foi investigar os rumos das pesquisas no ensino de biologia celular em dois eventos de relevância da área: os congressos promovidos pela Sociedade Brasileira de Biologia Celular (SBBC) e o Encontro Nacional de Pesquisa em Educação em Ciências (ENPEC). 


\section{Percurso metodológico}

Esta pesquisa de caráter exploratório consistiu na realização de um 'estado do conhecimento' das pesquisas no ensino de biologia celular em dois eventos de relevância para a área: Congressos da SBBC e ENPEC.

Gil (2008, p. 27) explica que as "pesquisas exploratórias são desenvolvidas com o objetivo de proporcionar visão geral, de tipo aproximativo, acerca de determinado fato". O mesmo autor ainda sinaliza que esses estudos são normalmente um primeiro passo para pesquisas posteriores e mais aprofundadas. Já as pesquisas denominadas como 'estado do conhecimento' são:

[...] uma contribuição importante na constituição do campo teórico de uma área de conhecimento, pois procuram identificar os aportes significativos da construção da teoria e prática pedagógica, apontar as restrições sobre o campo em que se move a pesquisa, as suas lacunas de disseminação, identificar experiências inovadoras investigadas que apontem alternativas de solução para os problemas da prática e reconhecer as contribuições da pesquisa na constituição de propostas na área focalizada. (ROMANOWSKI; ENS, 2006, p. 39).

Cabe ressaltar que "esses trabalhos não se restringem a identificar a produção, mas analisá-la, categorizá-la e revelar os múltiplos enfoques e perspectivas" (ROMANOWSKI; ENS, 2006, p. 39). Além disso, as mesmas autoras acrescentam que os estudos denominados como 'estado do conhecimento' divergem daqueles conhecidos por 'estado da arte', pois a investigação versa apenas sobre um setor das publicações, isto é, a pesquisa é voltada para as publicações de um evento específico ou para um periódico ou analisa dissertações e teses, sem necessariamente apreender todos os estudos de determinado tema.

Assim, como exposto anteriormente, optamos por buscar os trabalhos em dois eventos de relevância para a área. Cabe salientar que esta pesquisa dá continuidade às contribuições da pesquisa de Nascimento (2016), que realizou um levantamento nas Atas dos ENPEC realizados nos anos de 2009, 2011 e 2013, bem como nos Anais dos Congressos promovidos pela SBBC nos anos de 2010, 2012 e 2014. Para tanto, inicialmente buscamos por trabalhos nas Atas do ENPEC. Esse é um evento bienal, realizado pela Associação Brasileira de Pesquisa em Educação em Ciências - ABRAPEC desde 1997. Para esta pesquisa, realizamos um recorte temporal, investigando as Atas dos anos de 2015, 2017 e 2019, a partir dos termos predefinidos: I) biologia celular; II) citologia; III) célula. Todos estes termos foram identificados nos seguintes requisitos: título, resumo e/ou palavras-chave. Ao todo foram encontrados 34 trabalhos. Já as amostras extraídas dos Congressos promovidos pela SBBC, advêm da seção 'educação', na qual investigamos os anos de 2016 e 2018, o que nos forneceu 24 trabalhos. Esses Congressos ocorrem desde o ano de 1978, a cada dois ou três anos, e contam com a apresentação de trabalhos de diversos eixos temáticos, sendo um deles especial para a educação e o ensino em biologia celular.

No total, analisamos neste estudo, 58 trabalhos que foram lidos e agrupados em 12 categorias, a saber: 1) Modelos Didáticos; 2) Ferramentas Digitais de Aprendizagem; 3) Concepções Sobre Citologia; 4) Jogos; 5) Sequências Didáticas; 6) Formação de Professores; 7) Ensino Não-Formal; 8) Artigos de Revisão; 9) Atividades Práticas; 10) Análise de Livro Didático; 11) Textos de Divulgação Científica; 12) Outros. As categorias que empregamos foram baseadas naquelas criadas por Nascimento (2016), isto é, utilizamos nove categorias, $a$ 
priori. Todavia, ao realizar a leitura dos trabalhos, sentimos a necessidade da elaboração de mais três categorias. Esse processo se torna mais claro e evidente no decorrer do item Resultados e Discussão.

A fim de clarificar para o leitor, inicialmente apresentamos de forma breve os achados de Nascimento (2016). Após, apresentamos nossos resultados e promovemos um diálogo entre ambas as pesquisas, construindo uma linha do tempo das produções da década 2009-2019.

\section{Resultados e discussão}

A Tabela 1 foi por nós elaborada a partir dos dados elucidados por Nascimento (2016) e fornece os enfoques pesquisados tanto nos Congressos promovidos pela SBBC quanto nos ENPEC.

Tabela 1 - Número de trabalhos relacionados à área de biologia celular apresentados nos congressos promovidos pela SBBC (anos 2010, 2012, 2014) e nos ENPEC (anos 2009, 2011, 2013)

\begin{tabular}{c|c|c}
\hline Foco do trabalho & Total & \% \\
\hline Modelos Didáticos & 11 & 27 \\
Concepções Sobre Citologia & 5 & 12 \\
Atividades Práticas & 5 & 10 \\
Ferramentas Digitais de Aprendizagem & 4 & 10 \\
Jogos & 4 & 10 \\
Sequências Didáticas & 4 & 5 \\
Ensino Não Formal & 2 & 2 \\
Textos de Divulgação Científica & 1 & 12 \\
Outros & 5 & $\mathbf{1 0 0}$ \\
\hline TOTAL & $\mathbf{4 1}$ & \\
\hline
\end{tabular}

Fonte: Adaptada de Nascimento (2016).

Como podemos perceber através da Tabela 1, Nascimento (2016) demonstra que o interesse maior das pesquisas publicadas nos anos investigados, nos respectivos eventos citados, deteve-se aos Modelos Didáticos. Tal resultado ocorre porque provavelmente, como já explicitamos anteriormente, o ensino de biologia celular é considerado um tanto abstrato para o aluno e a criação de modelos pode contribuir para suprir a necessidade de visualizar os processos biológicos da célula pelos alunos, diminuindo assim essa abstração. Houaiss et al. (2004, p. 6), evidenciam que 'abstrato' significa “[...] que opera unicamente com ideias e suas associações e não diretamente com a realidade". Dessa forma, Sá et al. (2010, p. 03) explicam que fenômenos "submicroscópicos, muitas vezes compreendidos como abstratos, ocorrem em uma realidade não perceptível a nossos sentidos". Logo, a compreensão desses fenômenos se torna complexa, tendo em vista a impossibilidade de senti-los ou vê-los, como no caso da biologia celular.

Já as demais categorias (Concepções Sobre Citologia, Atividades Práticas, Ferramentas Digitais de Aprendizagem, Jogos, Sequências Didáticas e Outros) alcançam percentuais semelhantes entre eles nessa análise (entre 10 e $12 \%$ ), o que indica que a pesquisa na área está dissipada em variadas subáreas e eixos temáticos; isto é, há uma variedade de estratégias didáticas e temas pesquisados dentro da área. Conforme a própria autora, "as pesquisas têm demonstrado uma preocupação com a criação e divulgação de alternativas 
metodológicas que contribuam com a aprendizagem da Citologia e supram a carência de recursos e estrutura, fato comum nas escolas" (NASCIMENTO, 2016, p. 32). Merece destaque, ainda, que a categoria Outros criada pela autora, reúne trabalhos que não se encaixam em outras categorias e esses não são nomeados ou aprofundados no decorrer da sua investigação.

As áreas com menos trabalhos encontram-se relacionadas ao Ensino Não Formal e à utilização de Textos de Divulgação Científica para ensinar biologia celular. Tal fato pode ser preocupante pois, com a ausência da conscientização da população sobre diversos temas que envolvem a biologia celular, bem como com o estímulo às novas gerações acessarem textos confiáveis e de cunho científico, cai-se na tentação de acreditar em diversas fake news, tão conhecidas e disseminadas atualmente.

Sobre isso, Santos (2018), em seu estudo, discute temas biológicos a partir de fake news disseminadas na mídia. A partir de pesquisas realizadas pelos alunos, são encontradas 72 notícias falsas em redes sociais e na televisão. Ao final, a autora destaca que as notícias falsas, de uma forma geral, contam com algumas características interessantes de serem analisadas: (a) quem fala - normalmente as fake news não apresentam a assinatura de algum redator, tampouco a instituição ou a data de publicação, apenas conta com 'um cientista de renome'; (b) de onde fala - não há vinculação dos textos a instituições ou, em caso de notícias mais alarmistas, utilizando-se instituições renomadas como 'Harvard'; (c) como se fala - há presença de erros gramaticais e, por vezes, as notas são escritas em tom alarmista, como 'não há cura' ou 'há milhares de vítimas'; e, (d) ausência de referências - não há contraponto, nem discussões acerca do tema, expondo uma única ideia. Assim, estudos acerca não apenas da educação não formal, como também sobre a divulgação científica, são importantes para compreender de que forma a ciência chega à sociedade, bem como sua influência sobre as concepções de mundo dos indivíduos.

Nossos resultados apresentam algumas categorias com percentuais similares às sinalizadas por Nascimento (2016). Ainda assim, em nosso estudo sentimos a necessidade de elencar três categorias adicionais, em função do percentual significativo por elas alcançado, sendo estas: Artigos de Revisão, Formação de Professores e Análise do Livro Didático, apresentadas na Tabela 2.

Tabela 2 - Número de trabalhos relacionados à área de biologia celular apresentados nos congressos promovidos pela SBBC (anos 2016 e 2018) e nos ENPECs (anos 2015, 2017 e 2019)

\begin{tabular}{|c|c|c|c|c|c|c|c|}
\hline Categoria & $\begin{array}{c}\text { ENPEC } \\
2015 \\
\end{array}$ & $\begin{array}{l}\text { SBBC } \\
2016 \\
\end{array}$ & $\begin{array}{c}\text { ENPEC } \\
2017\end{array}$ & $\begin{array}{l}\text { SBBC } \\
2018 \\
\end{array}$ & $\begin{array}{c}\text { ENPEC } \\
2019 \\
\end{array}$ & Total & $\%$ \\
\hline Modelos Didáticos & 1 & 2 & 2 & 4 & 3 & 12 & 20,7 \\
\hline Ferramentas Digitais de Aprendizagem & 0 & 1 & 2 & 4 & 0 & 7 & 12,1 \\
\hline Concepções Sobre Citologia & 3 & 0 & 2 & 0 & 2 & 7 & 12,1 \\
\hline Jogos & 1 & 1 & 1 & 1 & 1 & 5 & 8,6 \\
\hline Sequências Didáticas & 1 & 1 & 0 & 1 & 2 & 5 & 8,6 \\
\hline Formação de Professores & 0 & 1 & 0 & 2 & 1 & 4 & 6,9 \\
\hline Ensino Não Formal & 0 & 1 & 0 & 2 & 0 & 3 & 5,2 \\
\hline Artigos de Revisão & 2 & 0 & 0 & 1 & 0 & 3 & 5,2 \\
\hline Atividades Práticas & 0 & 0 & 2 & 0 & 1 & 3 & 5,2 \\
\hline Análise de Livro Didático & 0 & 0 & 2 & 0 & 0 & 2 & 3,4 \\
\hline Textos de Divulgação Científica & 1 & 0 & 1 & 0 & 0 & 2 & 3,4 \\
\hline Outros & 0 & 1 & 0 & 1 & 3 & 5 & 8,6 \\
\hline TOTAL & 9 & 8 & 12 & 16 & 13 & 58 & 100 \\
\hline
\end{tabular}

Fonte: Elaborada pelas autoras (2020). 
Nos XVIII e XIX Congressos da SBBC, ocorridos em 2016 e 2018, respectivamente, foram encontrados 24 trabalhos ao todo, sendo oito no primeiro e 16 publicações no segundo (Tabela 2). Estes resultados mostram-se bastante relevantes, uma vez que nos anos de 2010, 2012 e 2014, Nascimento (2016) encontrou apenas 25 trabalhos, somando-se as três edições (Tabela 1). Já nas Atas dos ENPECs, foram encontrados 34 trabalhos, sendo nove na edição do ano de 2015, 12 trabalhos no ano de 2017 e 13 no ano de 2019 (Tabela 2), o que aponta igualmente um crescimento nas pesquisas, visto que Nascimento (2016) encontrou 16 trabalhos somando as edições de 2009, 2011 e 2013 (Tabela 1). Importante, ainda, destacar, que além do aumento total, esses são crescentes ao longo das edições. Tais resultados podem estar relacionados à ascensão da pesquisa em Ensino de Ciências no Brasil. Conforme Teixeira e Megid Neto (2012) esse crescimento inicia na década de 70 e desenvolve-se consideravelmente nas quatro décadas subsequentes, o que foi consequência do avanço da pós-graduação no país, e que fornece um maior número de profissionais pesquisadores e educadores científicos. Os mesmos autores ainda destacam que num primeiro momento, nos anos 70, as pesquisas voltadas ao ensino de biologia eram escassas. Todavia, com a formação de pesquisadores nos anos 80 e 90, essa área teve um crescimento significativo, à medida que os profissionais adentraram às universidades, continuaram pesquisando e orientando novos pesquisadores. Assim, houve a expansão da pesquisa em educação em ciências no Brasil.

Nossos resultados evidenciam que, novamente, Modelos Didáticos é a categoria que mais possui publicações, totalizando $20,7 \%$ da amostra para esta pesquisa, de modo semelhante ao encontrado por Nascimento (2016), que identificou para esta categoria um percentual de $27 \%$ do total de índice de publicações para os anos anteriores. De uma forma geral, esses trabalhos buscaram propor alternativas que pudessem contribuir para facilitar o aprendizado de conceitos abstratos da célula, pois "o Ensino de Biologia apresenta inúmeros conteúdos com abstrações que dificultam os processos de aprendizagens dos estudantes, um destes é a Biologia Celular, que por tratar de estruturas microscópicas, gera certo distanciamento aos educandos" (MARQUES, 2018, p. 01).

O resultado que encontramos abrange diversos públicos, desde a educação básica, como no trabalho de Leão et al. (2016), passando pelo ensino superior, como na investigação realizada por Reis et al. (2018), e também a educação não formal, como no artigo apresentado por Figueroa e Marandino (2017). O trabalho de Reis et al. (2018), por exemplo, apresenta a potencialidade da construção de um modelo interativo para explicar a gastrulação de anfíbios para ser utilizado na educação superior.

Já no trabalho de Luis et al. (2018), foi construído um modelo de célula dentro de uma sala de aula e, assim, os alunos de educação básica puderam sentir como se estivessem no interior de uma célula, passando a compreender melhor as suas estruturas e seu funcionamento. Outra pesquisa elucidada por Luiz et al. (2018) possibilita à comunidade local compreender o funcionamento celular, de forma semelhante ao trabalho anterior, isto é, construindo um modelo de célula gigante. Cabe ressaltar que, para além da construção de modelos, muitos dos trabalhos analisados buscaram investigar se esses recursos didáticos eram eficientes para ensinar biologia celular e se obtiveram resultados satisfatórios no uso desses materiais.

Assim, o emprego de modelos didáticos tem se configurado como uma alternativa enriquecedora ao ensinar biologia celular. Conforme Carlan, Sepel e Loreto (2013, p. 344), "os modelos são recursos que servem para simplificar fenômenos complexos e auxiliar na visualização de entidades complexas de modo a melhorar a compreensão do que está sendo estudado". Santos, Silva e Lima (2018, p. 180) ainda explicam sobre a trajetória do 
aprendizado do aluno a partir do uso de modelos didáticos: "O modelo didático passa pelo concreto, ao relacioná-lo à explicação teórica passa pelo concreto-abstrato e ao compreender o processo biológico, construindo seu conhecimento acerca dele, terá chegado à abstração".

Em contraponto à pesquisa anterior, Ferramentas Digitais de Aprendizagem apareceram em $12,1 \%$ dos trabalhos, sendo, portanto, outro ponto forte das pesquisas na área de biologia celular. Silva e Kalhil (2018, p. 81) expõem que:

\begin{abstract}
Vivemos em um mundo altamente tecnológico e, em constante evolução, em que ter um smartphone conectado à internet é uma necessidade básica. Neste ambiente virtual, onde imperam as tecnologias digitais e suas muitas faces (internet, aplicativos, redes sociais, mensageiros e etc), existe uma quantidade incalculável de informação disponível, sejam informações úteis e fidedignas, sejam informações falsas, tais como as recentes 'Fake News'. Neste contexto, percebe-se que o conhecimento e as informações disponíveis na rede mundial de computadores, ficam voláteis cada vez mais rápido, gerando dificuldades paras as pessoas filtrarem essa enorme massa de dados.
\end{abstract}

Igualmente, Silva e Kalhil (2018) caracterizam a atual geração como 'digital', pois já emprega naturalmente os mais diversos recursos digitais, sendo este um caminho sem volta. Ademais, Silva et al. (2006) afirmam que os professores não ficaram imunes a esse crescimento tecnológico, visto que fazem parte de uma cultura digital. A tecnologia possibilita uma gama de opções de recursos didáticos que têm auxiliado docentes a prepararem suas aulas, assim como alunos na confecção de trabalhos e pesquisas.

Logo, é natural o incremento no número de trabalhos voltados para esse tema, pois o uso dessas tecnologias tem sido compreendido como um facilitador no processo de aprendizado, sendo que, com a inserção da tecnologia disponível atualmente, muitos professores e pesquisadores têm buscado inovar nas metodologias ao ensinar. Dessa forma, trabalhos que versam sobre as mais diversas ferramentas disponíveis on-line têm ganhado grande repercussão, tendo em vista a explosão tecnológica em que estamos inseridos. Além disso, Nascimento (2016) corrobora afirmando que o emprego e a criação de ferramentas digitais de ensino e aprendizagem se estabelecem como um dos caminhos mais democráticos no acesso aos recursos e informações, o que proporciona motivação aos alunos no uso de materiais didáticos virtuais.

Na categoria Ferramentas Digitais, os trabalhos buscaram facilitar o aprendizado por meio da tecnologia, bem como instigar os alunos por meio do uso de blogs, sites, softwares e outros recursos digitais. O trabalho de Almeida, Nicácio e Correia (2017), por exemplo, utilizou um blog educacional para disponibilizar material didático, em que os próprios alunos foram responsáveis pela criação do blog com o auxílio do professor, o que fez com que esses fossem desafiados e pudessem compreender melhor a citologia. Em outra investigação, Santos et al. (2016) relataram a construção de um banco digital de imagens com riqueza científica voltadas para a pesquisa e educação, sobretudo para a área das ciências biomédicas.

As pesquisas relacionadas às Concepções Sobre Citologia alcançaram 12,1\% da amostra, semelhante aos $12 \%$ encontrados por Nascimento (2016). Conforme Pietrocola (1999), nas décadas de 1980 e 1990 do século passado, surgiu um movimento construtivista dentro do cenário educacional, no qual se levou em conta os saberes empíricos dos sujeitos, principalmente as concepções prévias, também conhecidas como ingênuas ou alternativas. 
As concepções prévias podem ser entendidas "como produtos dos esforços imaginativos das crianças para descrever e explicar o mundo físico que as rodeiam" (BRUM; SCHUHMACHER, 2014, p. 40). Pozo e Crespo (2009) acrescentam que tais concepções são geradas a partir das vivências cotidianas dos alunos, as quais ocorrem de forma espontânea e são fortemente resistentes à mudança. Assim, são de suma importância para uma aprendizagem significativa, em que novos saberes são agregados ao aparato cognitivo por meio da 'ancoragem' em saberes anteriores, isto é, o estudante sistematiza um novo conhecimento a partir de um conhecimento prévio anterior (AUSUBEL, 1982). Ademais, Kattmann (2001) discorre que na perspectiva construtivista, as concepções não podem ser transferidas do professor para os alunos, mas sim devem ser construídas pelos estudantes, de forma que elas façam sentido para eles. Dessa forma, as concepções prévias permitem ao professor buscar estratégias de ensino que favoreçam uma aprendizagem significativa para os discentes.

Assim, 12,1\% dos trabalhos que analisamos foram alvo das investigações acerca das concepções alternativas, a fim de utilizar essas concepções para iniciar a abordagem de determinados conteúdos científicos, com o intuito de desmistificar possíveis mitos em sala de aula. Isso justifica a preponderância e manutenção desse tipo de enfoque nas pesquisas, considerando sua importância para uma abordagem educacional construtivista.

Os trabalhos voltados aos Jogos apareceram em todas as edições dos eventos com $8,6 \%$ da amostragem total. Apesar de ainda ser um número relativamente baixo de trabalhos, são ferramentas utilizadas frequentemente para ensinar, pois promovem ludicidade, integração e diversão. Para além do supracitado, Damasceno e Marin (2017, p. 02) pontuam que:

\begin{abstract}
A sala de aula como um espaço social, representa lugar de convivência, interação com as outras pessoas, construção de afetos e de aprendizagens. Nesse contexto, o jogo e as atividades lúdicas não podem ser esquecidos no cotidiano escolar, são ferramentas que além de constituir uma alternativa de trabalhar de maneira atraente e envolvente os conteúdos com os alunos, também inserem os sujeitos na resolução de problemas, na interação com os colegas e na discussão de problemas de convivência.
\end{abstract}

Quando relacionado o jogo ao ensino de biologia celular, Dasmasceno e Marin (2017) ainda explicam que o principal desafio ao ensinar essa subárea biológica está relacionado ao uso de nomenclaturas científicas que requerem memorização. Ademais, Garcia e Nascimento (2017, p. 02) afirmam que "no ato do brincar, as crianças podem desenvolver muitas capacidades importantes, tais como a atenção, a imitação, a memória e a imaginação. [...] Por meio das brincadeiras, o aluno encontra apoio para superar suas dificuldades do aprendizado". Assim, os jogos podem motivar os alunos, além de facilitar os processos de ensino e de aprendizagem de conceitos celulares.

De modo semelhante, com $8,6 \%$ do total amostral, identificamos a categoria Sequências Didáticas. Cascais e Terán (2013, p. 02) explicam que "a sequência didática se constitui num método para o desenvolvimento de atividades de ensino e, dependendo da forma como é organizada, pode contribuir sobremaneira para a aprendizagem". Logo, trabalhos voltados à elaboração e exequibilidade de sequências didáticas podem auxiliar no entendimento da biologia celular.

Também com $8,6 \%$ do total amostral evidenciamos a categoria Outros, formada por uma diversidade de trabalhos, cujo assunto enfocado em cada um deles não se repete em nenhum outro. Dessa maneira, optamos por inseri-los numa categoria específica. A saber, os 
principais enfoques destes artigos estão relacionados à epistemologia da ciência, às dificuldades da área e às mudanças ocorridas no currículo para o ensino de biologia celular. Cabe ressaltar que essas áreas, ainda que com um número de pesquisas bastante restrito, são de extrema importância para a compreensão da dinâmica dos estudos e pesquisas na área da biologia celular. Pesquisas que levam em conta o currículo, por exemplo, permitem compreender como o cenário sócio histórico, permeado de interesses e conflitos políticos, influenciou e influencia na articulação dos conceitos a serem aprendidos em biologia celular (VIGÁRIO; CICILLINI, 2019). Logo, é relevante que esses eixos adentrem com maior expressividade no rol de estudos acerca da biologia celular.

A categoria Formação de Professores atingiu o percentual de 6,9\% e obteve um crescimento nas pesquisas no último ENPEC. Esses trabalhos contribuem exponencialmente para a melhoria das práticas pedagógicas dentro da sala de aula. Nossos resultados corroboram com o que salienta Bastos (2017, p. 01), ao afirmar que "nos últimos vinte anos, a temática da formação de professores vem se consolidando como uma das mais presentes nos trabalhos de pesquisa em educação em ciências".

Com apenas 5,2\% cada uma, evidenciamos as categorias Ensino Não-Formal, Artigos de Revisão e Atividades Práticas. As pesquisas atreladas ao ensino não formal são essenciais para aproximar a academia da sociedade. Sobre isso, Vaine e Lorenzetti (2017, p. 02) explicam:

\footnotetext{
Consideramos espaços não formais de ensino de Ciências todos os locais interessados em promover a divulgação científica e a sensibilização para a Ciência. Esses espaços recebem visitantes em suas dependências com ou sem o auxílio de monitores e alguns desenvolvem programas em parcerias com escolas por meio de palestras e fornecimento de materiais didáticos. Ou seja, são locais onde há a intenção de divulgar a Ciência, mesmo que não exista um currículo definido ou oferecimento de grau ou diploma. Assim, são exemplos: zoológicos, jardins botânicos, planetários, unidades de conservação, empresas, centros de ciências, museus, entre outros.
}

Ainda, os objetivos da educação não formal são elucidados por Gohn (2006, pp. 32-33), a saber:

\begin{abstract}
a) Educação para cidadania; b) Educação para justiça social; c) Educação para direitos (humanos, sociais, políticos, culturais, etc.); d) Educação para liberdade; e) Educação para igualdade; f) Educação para democracia; g) Educação contra discriminação; h) Educação pelo exercício da cultura, e para a manifestação das diferenças culturais
\end{abstract}

Logo, podemos inferir que o uso de espaços não formais pode contribuir para oportunizar às pessoas uma aproximação da ciência presente no seu dia a dia, uma vez que proporciona experiências e vivências em situações que não teriam dentro da sala de aula. Quando as pessoas adentram a esses locais passam a ter a possibilidade de uma participação social mais crítica e fundamentada, percebendo que a ciência é influenciada nos mais diferentes âmbitos, sociais, políticos e econômicos. Neste sentido, compreendem que a ciência não é neutra e traz consigo tanto benefícios, quanto possibilidades de problemas para a sociedade. Cabe ressaltar que por muito tempo a ciência vem sendo percebida publicamente 
como um processo neutro, objetivo e absoluto, o que 'cega' a população por meio de 'palavras mágicas’ como 'cientificamente comprovado' (SILVA, 2014).

Bazzo, Lisingen e Pereira (2003) ainda advertem que muitas pessoas confiam na ciência como se confia em uma divindade, demonstrando uma postura fortemente dogmática. Assim, tais estereótipos precisam ser quebrados, pois a atividade científica é dotada de interesses, conflitos e é socialmente construída. É preciso clarificar que a mesma ciência que desenvolve medicamentos para a cura de doenças, constrói bombas capazes de devastar cidades inteiras. Dessa forma, os espaços não-formais de educação podem atuar como uma forte ferramenta para a promoção de uma educação científica mais ampla e que contemple as diversas faces da ciência.

Os artigos de revisão tornam-se importantes à medida que fornecem diversos dados acerca de um mesmo tema. Assim, é possível compreender melhor a área de estudo de forma sintetizada. Os trabalhos de revisão são definidos por Noronha e Ferreira (2000, p. 191) como:

\footnotetext{
Estudos que analisam a produção bibliográfica em determinada área temática, dentro de um recorte de tempo, fornecendo uma visão geral ou um relatório do estado da arte sobre um tópico específico, evidenciando novas ideias, métodos, subtemas que têm recebido maior ou menor ênfase na literatura selecionada.
}

Em uma área de forte abstração e complexidade, como a biologia celular, é grave a incipiência de trabalhos dessa temática, pois são uma fonte de informação para pesquisadores e professores buscarem inovações e aprimoramentos para suas práticas profissionais. Assim, esses artigos fornecem uma riqueza de saberes de forma condensada, o que otimiza o tempo disponível do professor leitor, item que, por vezes, é escasso na vida docente, tendo em vista não apenas as altas cargas de trabalho, como também os poucos horários destinados ao planejamento pedagógico (GLASER; PIERRE; LARA-FIOREZE, 2017).

Ao comparar os resultados encontrados por Nascimento (2016) em relação aos nossos dados, pudemos encontrar um decréscimo nos trabalhos voltados para as Atividades Práticas, antes $12 \%$, agora $5,2 \%$. Esses dados podem ser reflexo do que ocorre em sala de aula. Ainda em 2001 Teixeira já alertava para alguns aspectos que deveriam merecer atenção especial dentro do ensino de biologia, dentre eles: o excesso de conteúdos e conceitos a serem ministrados, a metodologia de ensino e a diminuição do número de aulas reservadas à disciplina de biologia. Nesse sentido, por vezes, o professor em sala de aula é cobrado para que 'vença' o conteúdo planejado e, assim, não sobra tempo para as atividades práticas.

Uma outra hipótese é que, com a carência de laboratórios nas escolas brasileiras (NASCIMENTO, 2016), os professores limitem-se a aulas mais tradicionais ou com recursos cujo acesso é mais fácil. Tal fato não deveria ser um impeditivo, já que diversos estudos sinalizam outras possibilidades de aulas práticas para além dos laboratórios (SILVA; BALTAR; BEZERRA, 2019; SEPEL; ROCHA; LORETO, 2011; WALLAU et al., 2008). Entretanto, com a falta de investimentos tanto na estrutura física, quanto em pessoal, acreditamos que este fator se some a outros e atue como limitador de atividades práticas. Cabe enfatizar que em uma área de tamanha complexidade e abstração, tal resultado é preocupante, visto que, conforme Carlan, Sepel e Loreto (2013), muitas vezes os conceitos de biologia celular são trabalhados de forma desconexa da realidade dos alunos, logo, existe um repetido exercício de memorização de conceitos, o que inviabiliza uma aprendizagem significativa. 
Não obstante, os trabalhos voltados à Análise de Livro Didático e Textos de Divulgação Científica corresponderam, cada um, a 3,4\% do total amostral. Essas áreas são de extrema importância para o ensino de biologia celular. Se atentarmos para o fato de que o livro didático é o principal recurso utilizado na educação básica (GÜLLICH, 2013) e que muitos professores ainda o utilizam como o único recurso para planejarem e ministrarem suas aulas (CARLAN; SEPEL; LORETO, 2013), fica clara a necessidade de estudos e aprofundamentos sobre esse recurso. De modo semelhante, os mesmos autores enfatizam que, para uma aprendizagem significativa da biologia celular, é preciso diversificar os recursos didáticos, sendo assim, os textos de divulgação científica surgem como uma opção para o ensino sobre células. Esses textos podem ser definidos como recursos que comunicam informações científicas e tecnológicas para o público em geral (BUENO, 1984). Todavia, se por um lado eles informam a população, por outro há a disseminação de informações equivocadas. Rocha (2012, p. 134) adverte que:

\begin{abstract}
Atualmente, os meios de comunicação ajudam a promover uma aproximação entre o conhecimento científico e o cotidiano, sendo responsáveis por boa parte das informações que o público não especialista, incluindo os alunos de escolarização básica, possuem sobre ciência. Observando algumas notícias veiculadas nos meios de comunicação nos é possível inferir que frequentemente tratam de temáticas científicas da atualidade, relacionadas ao que está sendo produzido nos laboratórios. [...] Contudo, algumas informações contidas nos jornais e revistas são de casos específicos e, normalmente, não contextualizam a reportagem dentro do conjunto de conhecimentos já adquiridos. Desta forma, propagam-se e cristalizam-se conceitos equivocados que dificilmente serão revertidos.
\end{abstract}

Diante do exposto, é preciso um olhar atento a esse recurso que tem ganhado as salas de aula. Para que cumpram o seu papel pedagógico, os textos de divulgação científica precisam contar com informações corretas e conexas aos conhecimentos adquiridos anteriormente. Assim, consideramos os percentuais encontrados tanto para Análise do Livro didático quanto para Textos de Divulgação Científica, incipientes, tendo em vista a sua importância para o ensino.

Ao fim desta discussão, apresentamos um gráfico (Figura 1) que contém uma linha do tempo das publicações ano a ano (de 2009 a 2019), seja nos encontros do ENPEC (anos 2009, 2011, 2013, 2015, 2017, 2019), ou nos congressos promovidos pela SBBC (anos 2010, 2012, 2014, 2016, 2018). Salientamos que este gráfico foi elaborado com dados de Nascimento (2016), (de 2009 até 2014), destacado no gráfico em tom azul claro, em continuidade com os resultados investigados nesta pesquisa (de 2015 a 2019), destacado no gráfico em tom azul escuro.

Na década 2009-2019 foram publicados 99 trabalhos voltados para o ensino de biologia celular nestes dois eventos (ENPECs e Congressos da SBBC). Ao observar o gráfíco, é possível perceber uma instabilidade no número de trabalhos ao longo dos anos, com uma maior produção nos anos de 2012, 2017, 2018 e 2019. Ainda assim, podemos afirmar que houve uma elevação no número de trabalhos, sobretudo nos três últimos anos analisados. Se compararmos os anos de 2009 e 2019, perceberemos um salto de 4 para 13 artigos publicados. Tal evolução provavelmente esteja ligada à ampliação da pós-graduação no Brasil, o que gerou um aumento no número de profissionais pesquisadores qualificados dentro do Ensino de Ciências (SLONGO; LORENZETTI; GARVÃO, 2019; TEIXEIRA; MEGID NETO, 2012). 
Ademais, esse resultado se alinha ao que tem se evidenciado em outras pesquisas do tipo 'estado do conhecimento' (CABRAL et al., 2019; DELIZOICOV; SLONGO; LORENZETTI, 2013; ROSA et al., 2020; SÁ et al., 2011; SLONGO; LORENZETTI; GARVÃO, 2019), em que existe um crescimento no número total de trabalhos. Ainda assim, Silva e Gamboa (2011, p. 376) explicam que se por um lado "[...] a insuficiência de produção científica engendra problemas, a geração de conhecimentos sem criticidade e fragmentada, também os cria, visto que muitas vezes não propicia uma leitura precisa da realidade". Nesse sentido, é preciso fortalecer os programas de pós-graduação, para a formação de pesquisadores qualificados e comprometidos com o rigor necessário para a atividade científica. Além disso, políticas públicas para o financiamento de pesquisas na área necessitam ser fomentadas com o propósito de contemplarem diversas necessidades emergentes no ensino de ciências.

Figura 1 - Número total de trabalhos apresentados nos congressos promovidos pela SBBC (anos 2010, 2012, 2014, 2016 e 2018) e nos ENPEC (anos 2009, 2011, 2013, 2015, 2017 e 2019), relacionados à área de biologia celular

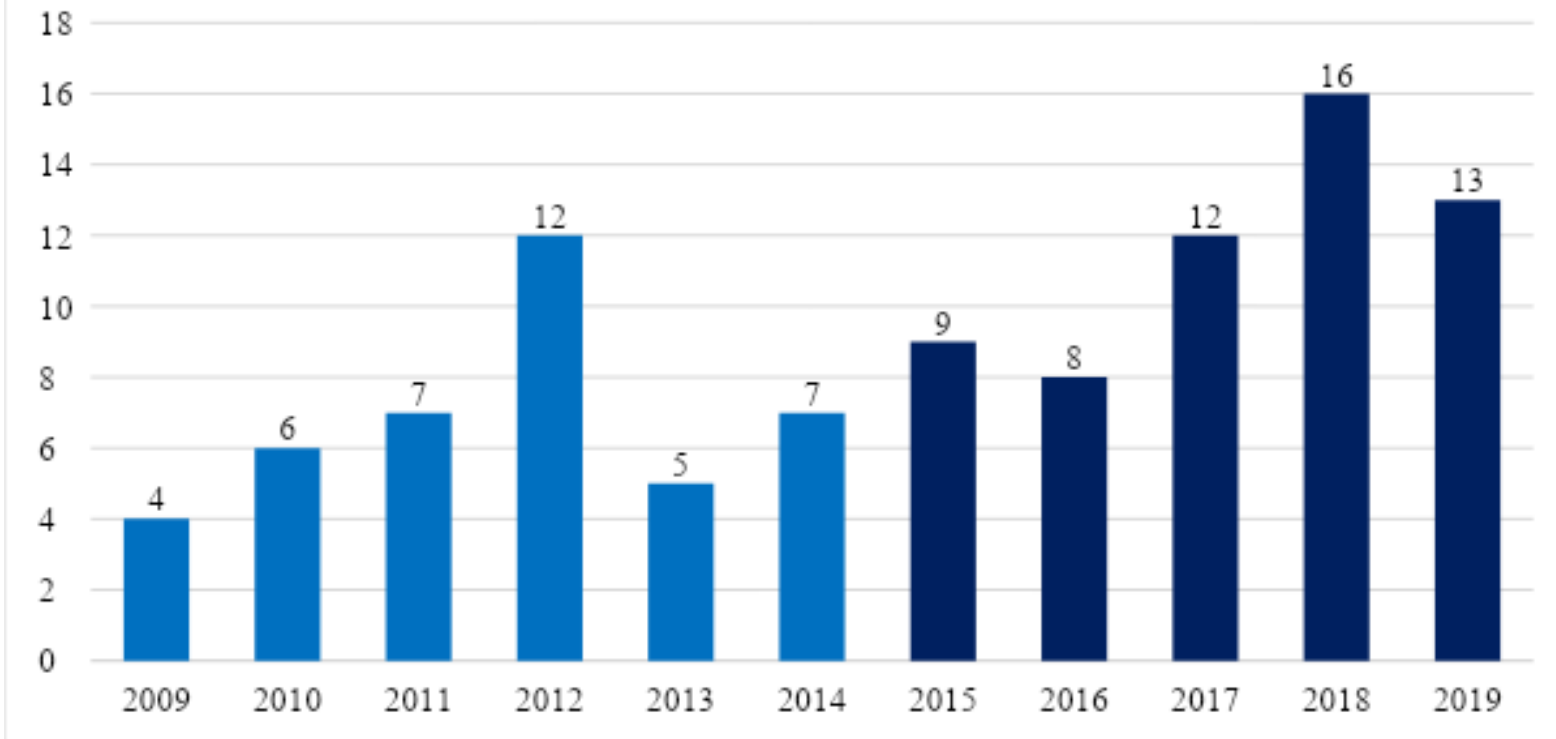

Fonte: Elaborada pelas autoras (2020) com dados próprios nos anos de 2015 a 2019 e adaptado de Nascimento (2016) nos anos de 2009 a 2014.

Curiosamente, no ano de 2019 menos artigos foram publicados em comparação ao ano anterior. Cabe sinalizar que esses dados tratam de eventos diferentes. Enquanto que em 2018 ocorria o XIX Congresso de Biologia Celular, em 2019 aconteceu o XII ENPEC. Todavia, ao buscar pelo número geral de trabalhos aprovados nos anos de 2017 e 2019 no ENPEC, temos uma diminuição de 1.335 para 1.249 trabalhos publicados na última edição. Cabe mencionar que o número de submissões também é decrescente (de 1.840 para 1.752). Assim, ainda que em nossa investigação tenhamos encontrado um sutil crescimento nas publicações, comparando os anos de 2017 e 2019, em termos gerais há uma diminuição das pesquisas na área do ensino de ciências.

Tal fato deve ser visto como um alerta e pode estar ocorrendo em consequência dos constantes cortes em bolsas de pesquisa e financiamento de projetos na área da educação e, consequentemente, no ensino de ciências. Importa destacar que no Brasil a pesquisa científica é financiada, principalmente, pelas agências de fomento, com destaque para Coordenação de 
Aperfeiçoamento de Pessoal de Nível Superior (Capes), o Conselho Nacional de Desenvolvimento Científico e Tecnológico $(\mathrm{CNPq})$ e as Fundações de Amparo à Pesquisa (FAPs). Esse cenário, caracterizado como perverso por De Vasconcelos et al. (2021), resulta em poucos projetos financiados, escassa produção de artigos e consequentemente, baixa produção na área.

Ademais, Fávero e Bechi (2017, p. 91) explicam que o "financiamento da pesquisa e da pós-graduação nas Instituições Federais de Ensino Superior (IFES) apresenta sinais inconfundíveis de que está ocorrendo um processo de mercantilização da educação". E isso ocorre em consequência de o Estado apoiar um grupo minoritário elitizado, o qual tem seus interesses ideológicos atendidos. Severino $(2008$, p. 86) corrobora com esta afirmação ao denunciar que "ao invés de estar a serviço dos interesses universais da população, o aparelho estatal atua como se fosse entidade privada, a serviço de interesses particulares". O mesmo autor ainda explicita que há um significativo dilema no ensino superior brasileiro:

[...] o confronto entre uma educação pautada nas premissas da teoria do capital humano e uma educação que se quer identificada com a teoria da emancipação humana, entre uma educação que se coloca a serviço do mercado e uma outra que se quer a serviço da construção de uma condição de existência mais humanizada, onde o trabalho é uma mediação essencial do existir histórico das pessoas e não um mero mecanismo da produção para o mercado (SEVERINO, 2008, p. 87).

A partir daí surgem, conforme De Vasconcelos et al. (2021, p. 21268-21269) problemas e alguns fatores inquietantes:

\begin{abstract}
Atrasos na liberação de recursos pelas entidades de fomento, recursos ineficientes e mal distribuídos, obstáculos burocráticos, infraestruturas inadequadas, [...] falta de equipamentos, reduzido apoio técnico e operacional, [...] cortes de verbas para andamento e desenvolvimento de futuras pesquisas, bem como em bolsas para pesquisadores nas diversas modalidades.
\end{abstract}

Logo, é preciso resistir e lutar para que a educação pública superior do país não fique à mercê da falta de interesse em fortalecê-la, transformando-a meramente em um produto. Assim, Fávero e Bechi (2017) expõem alguns caminhos que podemos seguir a fim de evitar o desmonte da educação pública superior, fortalecendo os espaços democráticos:

[...] ampliar os fóruns de debates sobre a ideia da educação como um bem público, publicizar o processo de empresariamento da educação que está acontecendo no Brasil, sensibilizar e mobilizar a sociedade para que compreenda os riscos que tal processo significa na produção da deterioração da sociedade democrática. (FÁVERO; BECHI, 2017. p. 107).

Ao voltar essa problemática para o ensino de biologia, podemos inferir que a falta de recursos para a pesquisa tende a intensificar os problemas da área, tendo em vista que, com um menor número de estudos, menos saberemos da realidade das escolas, das lacunas e necessidades da área. Assim, o impacto desse desmonte afeta não apenas as universidades e 
os programas de pós-graduação, mas sim toda a sociedade, à medida que melhorias advindas da pesquisa científica deixam de ser implementadas.

\section{Considerações finais}

Os resultados evidenciam um aumento no número de trabalhos voltados para a área de biologia celular ao longo dos anos de 2009 a 2019. Ainda assim, o ano de 2019 apresentou um decréscimo no número de trabalhos publicados com a temática biologia celular. Este fato pode estar ligado aos recorrentes cortes de bolsas de pesquisa e financiamento de projetos, que inviabilizam parte do trabalho dos pesquisadores e avanços na área.

As categorias Modelos Didáticos, Ferramentas Digitais de Aprendizagem e Concepções Sobre Citologia foram os focos mais pesquisados nos trabalhos investigados, logo os consideramos potencialidades dentro da área. A busca por modelos tem se configurado como uma alternativa capaz de superar as dificuldades dos estudantes, tendo em vista a complexidade e abstração que o ensino de biologia celular possui. Ademais, com a atual explosão tecnológica, cada vez mais os recursos digitais permeiam o processo de ensino e de aprendizagem, fato evidenciado pelo aumento significativo das pesquisas investigadas nesse recorte temporal. Já as concepções prévias têm sido exploradas no ambiente escolar, visando a construção de saberes a partir dos conhecimentos dos alunos e, assim, pode proporcionar uma aprendizagem significativa e condizente com o interesse do estudante.

Na contramão, as categorias Formação de Professores, Análise de Livro Didático, e Textos de Divulgação Científica possuem percentuais pouco expressivos, o que é preocupante, à medida que esses eixos alicerçam o ensino escolar e se fazem presentes no dia a dia da sala de aula. Assim, sinalizamos uma lacuna nas pesquisas e reiteramos a importância de novos trabalhos voltados para essas áreas, a fim de contribuir com o fornecimento de apoio pedagógico aos professores, na busca de fragilidades e soluções de problemas nos processos formativos, como a análise de recursos didáticos amplamente empregados, suas potencialidades e limitações.

Ao final, esperamos contribuir para o aprimoramento das pesquisas na área, ao ter indicado potencialidades, lacunas e fragilidades a serem preenchidas com novos estudos no ensino de biologia celular, almejando colaborar para o fortalecimento da educação científica no país.

\section{Referências}

ALBERTS, Bruce et al. Biologia molecular da célula. Porto Alegre: Artmed, 2017.

ALMEIDA, Adriana Gomes de; NICÁCIO, Saulo Verçosa; CORREIA, Monica Dorigo. O uso do blog como ferramenta educacional estratégica no ensino de Ciências. In: ENCONTRO NACIONAL DE PESQUISA EM EDUCAÇÃO EM CIÊNCIAS, 9., 2017, Florianópolis. Anais [...]. Florianópolis: ABRAPEC, 2017.

AUSUBEL, David. P. A aprendizagem significativa: a teoria de David Ausubel. São Paulo: Moraes, 1982.

BASTOS, Fernando. A pesquisa em educação em ciências e a formação de professores.

Ciência \& Educação, Bauru, v. 23, n. 2, p. 299-302, jun., 2017. 
BAZZO, Walter.; LISINGEN, Irlan von.; PEREIRA, Luiz. Teixeira do Vale. Introdução aos Estudos CTS (Ciência, Tecnologia e Sociedade). Cadernos de Ibero América.

OEI-Organização dos Estados Ibero-americanos para a Educação, a Ciência e a Cultura.

Espanha: Madrid, 2003.

BRUM, Wanderley Pivatto; SCHUHMACHER, Elcio. A importância das concepções alternativas na apropriação do conhecimento: a aplicação no estudo de bactérias no ensino fundamental e suas implicações para a saúde humana. Revista ARETÉ, Manaus, v.7, n.13, p.38-47, jan/jun., 2014.

BUENO, Wilson da Costa. Jornalismo científico no Brasil: compromissos de uma prática dependente. 1984. Tese (Doutorado em Comunicação e Arte) - Universidade de São Paulo, 1984.

CABRAL, Laertty Garcia de Sousa; ALVES, Monique Gonçalves.; ALVES, Rosely Cabette Barbosa; GEGLIO, Paulo César. O estado do conhecimento sobre o ensino de ciências: a produção em dissertações e teses. In: DURAU, Karina. Demandas e contextos da educação no século XXI 2. Ponta Grossa: Atena, 2019.

CARLAN, Francele de Abreu; SEPEL, Lenira Maria Nunes; LORETO, Élgion Lúcio da Silva. Explorando diferentes recursos didáticos no Ensino Fundamental: uma proposta para o ensino de célula. Acta Scientiae, v. 15, n.2, p. 338-353, maio/ago, 2013.

CASCAIS, Maria das Graças Alves; TERÁN, Augusto Fachin. Sequências didáticas nas aulas de ciências do ensino fundamental: possibilidade para a alfabetização científica. In:

ENCONTRO NACIONAL DE PESQUISA EM EDUCAÇÃO EM CIÊNCIAS, 9., 2013, Águas de Lindóia. Anais [...]. Águas de Lindóia: ABRAPEC, 2013.

DAMASCENO, Maria Tatiane Souza; MARIN, Yonier Alexander Orozco. O jogo como ferramenta para o ensino e motivador da aprendizagem de conceitos associados ao tema citologia no Ensino Fundamental. In: ENCONTRO NACIONAL DE PESQUISA EM EDUCAÇÃO EM CIÊNCIAS, 9., 2017, Florianópolis. Anais [...]. Florianópolis: ABRAPEC, 2017.

DELIZOICOV, Demétrio; SLONGO, Iône Inês Pinsson; LORENZETTI, Leonir. Um panorama da pesquisa em educação em ciências desenvolvida no Brasil de 1997 a 2005.

Revista Electrónica de Enseñanza de las Ciencias, Barcelona, v. 12, n. 3, p. 459-480, 2013.

DE VASCONCELOS, Pedro Fonseca et al. Financiamento da pesquisa no Brasil ao longo de dez anos. Brazilian Journal of Development, v. 7, n. 3, p. 21258-21271, 2021.

FÁVERO, Altair Alberto; BECHI, Diego. O financiamento da educação superior no limiar do século XXI: o caminho da mercantilização da educação. Revista Internacional de Educação Superior. Campinas, SP, v. 3 n. 1 p. 90-113, jan./abr. 2017.

NORONHA, Daisy Pires; FERREIRA, Sueli Mara S. P. Revisões de literatura. In:

CAMPELLO, Bernadete Santos; CONDÓN, Beatriz Valadares; KREMER, Jeannette 
Marguerite (org.) Fontes de informação para pesquisadores e profissionais. Belo Horizonte: UFMG, 2000.

FIGUEROA, Ana Maria Senac; MARANDINO, Martha. O modelo de célula gigante: um estudo da transposição museográfica nos museus de ciências. In: ENCONTRO NACIONAL DE PESQUISA EM EDUCAÇÃO EM CIÊNCIAS, 9., 2017, Florianópolis. Anais [...]. Florianópolis: ABRAPEC, 2017.

GARCIA, Lilian Fialho Costa; NASCIMENTO, Patrícia Maria Pereira do. O jogo didático no ensino de ciências: uma análise do jogo "descobrindo o corpo humano". In: ENCONTRO NACIONAL DE PESQUISA EM EDUCAÇÃO EM CIÊNCIAS, 9., 2017, Florianópolis. Anais [...]. Florianópolis: ABRAPEC, 2017.

GIL, Antônio Carlos. Métodos e técnicas de pesquisa social. 6. ed. São Paulo: Atlas, 2008.

GLASER, Viviane; PIERRE, Patrícia Maria Oliveira; LARA-FIOREZE, Ana Carolina da Costa. Estratégias didático-pedagógicas como alternativas para o ensino de Biologia Celular: curso aos professores de escolas públicas de Ensino Médio de Curitibanos-SC. Revista de Ensino de Bioquímica, v. 15, n. 2, 2017.

GOHN, Maria da Glória. Educação não formal, participação da sociedade civil e estruturas colegiadas nas escolas. Ensaio: Avaliação e Políticas Públicas em Educação, Rio de Janeiro, v. 14, n. 50, p. 27-38, jan./mar., 2006,

GÜLLICH, Roque Ismael da Costa. Investigação-formação-ação em Ciências: um caminho para reconstruir a relação entre livro didático, o professor e o ensino. 1. ed. Curitiba, PR: Prismas, 2013.

HOUAISS, Antônio; VILLAR, Mauro de Salles; FRANCO, Francisco Manoel de Mello. Minidicionário Houaiss da língua portuguesa. Rio de Janeiro: Objetiva, 2004.

KATTMAN, Ulrich. Aquatics, Flyers, Creepers and Terrestrials students' conceptions of animal classification. Journal of Biological Education, n. 35, 2001.

LEÃO, Gabriel Mathias Carneiro et al. Using non-linguistic representations to the cell biology education: a case study. In: CONGRESSO DA SOCIEDADE BRASILEIRA DE BIOLOGIA CELULAR, 18., 2016, São Paulo. Anais [...]. São Paulo: SBBC, 2016.

LUIS, Thiago et al. Teaching cell biology inside a macro-cell. In: CONGRESSO DA SOCIEDADE BRASILEIRA DE BIOLOGIA CELULAR, 19., 2018, São Paulo. Anais [...]. São Paulo: SBBC, 2018.

LUIZ, Thiago et al. Macro-cell: bringing the scientific knowledge of cell biology closer to community. In: CONGRESSO DA SOCIEDADE BRASILEIRA DE BIOLOGIA CELULAR, 19., 2018, São Paulo. Anais [...]. São Paulo: SBBC, 2018.

MARQUES, Keiciane Canabarro Drehmer. Modelos didáticos comestíveis como uma técnica de ensino e aprendizagem de biologia celular. \# Tear: Revista de Educação Ciência e Tecnologia, Canoas, v. 7, n. 2, 2018. 
NASCIMENTO, Jane Victal do. Citologia no ensino fundamental: dificuldades e possibilidades na produção de saberes docentes. 2016. Dissertação (Mestrado em Ensino na Educação Básica) - Centro Universitário Norte do Espírito Santo, Programa de Pós-Graduação em Ensino na Educação Básica, Universidade Federal do Espírito Santo, 2016.

POZO, Juan Ignacio; CRESPO, Miguel Ángel Gómes. Aprendizagem e o ensino de Ciências: do conhecimento cotidiano ao conhecimento científico. 5. ed. Porto Alegre: Artmed, 2009.

REIS, Camila A. dos et al. The use of interactive model for the study of aspects of frog gastrulation. In: CONGRESSO DA SOCIEDADE BRASILEIRA DE BIOLOGIA CELULAR, 19., 2018, São Paulo. Anais [...]. São Paulo: SBBC, 2018.

ROCHA, Marcelo Borges. Contribuições dos textos de divulgação científica para o ensino de Ciências na perspectiva dos professores. Acta Scientiae, v. 14, n. 1, jan./abr. 2012.

ROMANOWSKI; Joana Paulin; ENS, Romilda Teodora. As pesquisas denominadas do tipo "estado da arte" em educação. Diálogo Educacional, Curitiba, v. 6, n. 19, p. 37-50, set./dez. 2006.

ROSA, Márcia Prado Amaral et al. Ensino em ciências na educação infantil e nos anos iniciais: panorama das pesquisas divulgadas na década de 2007-2017 no ENPEC. Revista de Educação, Ciências e Matemática, v.10, n.1, jan./abr., 2020.

SÁ, Luciana Passos et al. Análise das pesquisas sobre EJA nos Encontros Nacionais de Pesquisa em Educação em Ciências. In: ENCONTRO NACIONAL DE PESQUISA EM EDUCAÇÃO EM CIÊNCIAS, 8., 2011, Campinas. Anais [...]. Campinas: ABRAPEC, 2011.

SÁ, Risonilda Germano Bezarra et al. Conceitos abstratos: um estudo no ensino da biologia. Revista da SBEnBio, n. 03, out. 2010.

SANTANA, Juliane Maria de; SANTOS, Caique Barbosa dos. O Uso de Modelos Didáticos de Células Eucarióticas como instrumentos facilitadores nas aulas de Citologia do Ensino Fundamental. Id on Line - Revista Multidisciplinar e de Psicologia. v.13, n. 45, SUPLEMENTO 1, p.155-166, 2019.

SANTOS, Beatriz Viana dos et al. Bioimagem: an open access center for cellular and molecular imaging sharing, education and research in biomedical sciences. In: CONGRESSO DA SOCIEDADE BRASILEIRA DE BIOLOGIA CELULAR, 18., 2016, São Paulo. Anais […]. São Paulo: SBBC, 2016.

SANTOS, Rodrigo de Oliveira; SILVA, Priscila Santos da; LIMA, Jandra Lúcia de Souza. Modelo didático como recurso para o ensino de ciências: sua influência como ferramenta facilitadora no processo de ensino aprendizagem. Revista Vivências em Ensino de Ciências, v. 2, 2018. 
SANTOS, Telma Temoteo dos. As fake news e o ensino de Ciências e Biologia. Revista Educação Pública, set. 2018.

SEPEL, Lenira Maria Nunes; ROCHA, João Batista Teixeira da; LORETO, Élgion Lúcio da Silva. Construindo um microscópio II. Bem simples e mais barato. Genética na Escola, São Paulo, 2011.

SEVERINO, Antônio Joaquim. O ensino superior brasileiro: novas configurações e velhos desafios. Educar, Curitiba, n.31, p.73-89, 2008.

SILVA, Bruna Herculano da. A perspectiva CTS na formação inicial de professores de química: construindo subsídios para uma ação didático-pedagógica inovadora. 2014.

Dissertação (Mestrado em Ensino das Ciências) - Programa de Pós-Graduação em Ensino das Ciências, Universidade Federal Rural de Pernambuco, 2014.

SILVA, Henrique Cesar da et al. Cautela ao usar imagens em aulas de ciências. Ciência \& Educação, Bauru, v. 12, n. 2, p. 219-233, 2006.

SILVA, José Junio da; BALTAR, Solma Lúcia Souto Maior de Araújo; BEZERRA, Maria Lusia de Moraes Belo. Experimentação em ciências com o uso de um microscópio artesanal e corante alternativo. Experiências em Ensino de Ciências. v. 14, n. 1, 2019.

SILVA, Régis Henrique dos Reis; GAMBOA, Sílvio Sánchez. Análise epistemológica da pesquisa em Educação Especial: a construção de um instrumento de análise. Atos de Pesquisa em Educação, Blumenau, v. 6, n. 2, p. 373-402, 2011.

SILVA, Wender Antônio da; KALHIL, Josefina Barrera. Tecnologias digitais no ensino de ciências: reflexões e possibilidades na construção do conhecimento científico. Revista Brasileira de Educação em Ciências e Educação Matemática, Cascavel, v. 2, n. 1, p. 77-91, abr. 2018.

SLONGO, Iône Inês Pinsson; LORENZETTI, Leonir; GARVÃO, Marzane. Explicitando dados e analisando tendências da pesquisa em Educação em Ciências no Brasil: uma análise da produção científica disseminada no ENPEC. Revista Brasileira de Ensino de Ciências e Matemática, Passo Fundo, v. 2, n. 2, p. 180-206, jul./dez. 2019.

TEIXEIRA, Paulo Marcelo Marini. Reflexões sobre o Ensino de Biologia realizado em nossas escolas. In: ENCONTRO NACIONAL DE PESQUISA EM EDUCAÇÃO EM CIÊNCIAS, 3., 2001, Atibaia. Anais [...]. São Paulo, 2001.

TEIXEIRA, Paulo Marcelo Marini; MEGID NETO, Jorge. O estado da arte da pesquisa em ensino de Biologia no Brasil: um panorama baseado na análise de dissertações e teses.

Revista Electrónica de Enseñanza de las Ciencias, v. 11, n. 2, p. 273-297, 2012.

VAINE, Thais Eastwood; LORENZETTI, Leonir. Potencialidades dos espaços não formais de ensino para a Alfabetização Científica: um estudo em Curitiba e Região Metropolitana. In: ENCONTRO NACIONAL DE PESQUISA EM EDUCAÇÃO EM CIÊNCIAS, 9., 2017, Florianópolis. Anais [...]. Florianópolis: ABRAPEC, 2017. 
VIGÁRIO, Ana Flávia.; CICILLINI, Graça Aparecida. Os saberes e a trama do ensino de Biologia Celular no nível médio. Ciência \& Educação, Bauru, v. 25, n. 1, p. 57-74, jan. 2019.

WALLAU, Gabriel da Luz et al. Construindo um microscópio, de baixo custo, que permite observações semelhantes às dos primeiros microscopistas. Revista Genética na Escola, n. 3, p. 1-3, 2008.

Recebido em dezembro de 2020.

Aprovado em maio de 2021. 